\title{
Inactivation of Escherichia coli K12 in phosphate buffer saline and orange juice by high hydrostatic pressure processing combined with freezing
}

Article

Accepted Version

Creative Commons: Attribution-Noncommercial-No Derivative Works 4.0

Bulut, S. and Karatzas, K. A.G. (2021) Inactivation of Escherichia coli K12 in phosphate buffer saline and orange juice by high hydrostatic pressure processing combined with freezing. LWT-Food Science and Technology, 136 (1). 110313. ISSN 0023-6438 doi: https://doi.org/10.1016/j.Iwt.2020.110313 Available at https://centaur.reading.ac.uk/94832/

It is advisable to refer to the publisher's version if you intend to cite from the work. See Guidance on citing.

To link to this article DOI: http://dx.doi.org/10.1016/j.Iwt.2020.110313

Publisher: Elsevier

All outputs in CentAUR are protected by Intellectual Property Rights law, including copyright law. Copyright and IPR is retained by the creators or other copyright holders. Terms and conditions for use of this material are defined in the End User Agreement. 


\section{CentAUR}

Central Archive at the University of Reading

Reading's research outputs online 


\title{
Inactivation of Escherichia coli K12 in phosphate buffer saline and orange juice by high hydrostatic pressure processing combined with freezing
}

\author{
Sami Bulut*1,2 and Kimon A. G. Karatzas ${ }^{1}$ \\ ${ }^{1}$ Department of Food \& Nutritional Sciences, School of Chemistry, Food \& Pharmacy, University of \\ Reading, Reading, RG6 6AD, UK \\ 2* Corresponding author's current address: Trakya University, Faculty of Engineering, Department of \\ Food Engineering, 22030, Edirne, TURKEY, e-mail: samibulut@trakya.edu.tr
}




\section{Abstract}

2 Synergistic action of high hydrostatic pressure (HHP) and freezing on inactivation of Escherichia coli

$3 \quad \mathrm{~K} 12$ in phosphate buffered saline (PBS) was investigated by employing response surface methodology. Samples containing E. coli $\mathrm{K} 12$ were stored at $4,-24$ and $-80^{\circ} \mathrm{C}$ overnight before they were pressurized. A maximum of $1.83 \mathrm{log}$ reduction of $\mathrm{CFU} \cdot \mathrm{ml}^{-1}$ was obtained following a 9-min treatment at $400 \mathrm{MPa}$ and $4 \pm 1{ }^{\circ} \mathrm{C}$ in samples stored at $4{ }^{\circ} \mathrm{C}$ whereas, 5.63 and 6.83 log reductions were obtained in samples frozen at -24 and $-80^{\circ} \mathrm{C}$, respectively. Major disruption of $E$. coli cells observed by scanning electron microscopy and increased amounts of DNA and RNA measured in

Keywords: High hydrostatic pressure processing, Escherichia coli, cell rapture, frozen state, orange juice. samples was due to cell rapture. The validity of enhanced microbial inactivation by freezing before HHP for a real food system was tested by using orange juice. Pressurization ( $250 \mathrm{MPa}, 15 \mathrm{~min}$ ) of frozen $\left(-80^{\circ} \mathrm{C}\right)$ orange juice resulted in $4.88,4.15$ and $4.61 \mathrm{log} \mathrm{CFU} \cdot \mathrm{ml}^{-1}$ reductions in number of $E$. coli for the samples having pH 3.2, 4.5 and 5.8, respectively. In the absence of freezing, the same treatment caused only up to 0.42 log reduction in samples having $\mathrm{pH} 4.5$ and 5.8. 


\section{INTRODUCTION}

High hydrostatic pressure processing (HHP) is a non-thermal method for inactivating microorganisms in food matrices and other biomaterials (Luscher, Balasa, Fröhling, Ananta, \& Knorr, 2004) that are sensitive to heat. As one of the most promising non-thermal processing technologies, HHP is already used in the food industry around the world. However, the usage of this method is limited due to high equipment cost. Therefore, the scientific community has been focusing on reducing the intensity of processing by minimising pressures or times. This is normally achieved through the use of hurdle technology by combining other stresses with HHP aiming to reduce operational costs (Huang, Wu, Lu, Shyu, \& Wang, 2017).

In recent years, few studies have focused on a possible synergistic action of HHP and freezing on microbial inactivation when foods or model food systems are frozen prior to pressurization at ambient or subzero temperatures. Luscher, et al. (2004) achieved reductions of a 2.5 and 2.9 log cycles of CFU $\cdot \mathrm{ml}^{-1}$ for Listeria innocua BGA 3532 at $400 \mathrm{MPa}$ and subzero temperatures (PBS, pH 7.0) with zero holding times at $-45^{\circ} \mathrm{C}$. The high rate of microbial inactivation was explained by the mechanical stress associated with the phase transition of ice I to other ice polymorphs (ice II or ice III) during pressurization.

Working with Bacillus subtilis vegetative cells in ACES ( $\mathrm{pH}$ 8.5), Shen, Urrutia Benet, Brul, and Knorr (2005) showed that a $20 \mathrm{~s}$ treatment at 250 and $350 \mathrm{MPa}$ at $-25^{\circ} \mathrm{C}$ on frozen cell suspensions resulted in more than $4 \log$ reduction of CFU. $\mathrm{ml}^{-1}$. The authors suggested that solid-solid phase transitions were mainly responsible for the observed drop in cell viability.

Bulut (2014b) showed that a 5 min pressure treatment at $300 \mathrm{MPa}$ and $0{ }^{\circ} \mathrm{C}$ resulted in 1.8 log cycles of CFU $\cdot \mathrm{ml}^{-1}$ reduction in numbers of $E$. coli strain ATCC 25922 in milk. Freezing the samples at $-21^{\circ} \mathrm{C}$ overnight prior to pressurization under the same conditions increased the log reduction to 5.2 log $\mathrm{CFU} \cdot \mathrm{ml}^{-1}$. Another study conducted on minced meat inoculated with E. coli strain ATCC 25922 resulted in 3.0 log reduction after a 5 min pressure treatment of frozen samples (at $-21^{\circ} \mathrm{C}$ ) at 300 $\mathrm{MPa}$ and $-5^{\circ} \mathrm{C}$, whereas only a reduction of $1.5 \log$ unit was obtained in pressure treated unfrozen samples (Bulut, 2014).

Su, Yu, Ramaswamy, Hu, Xu, and Zhu (2014) investigated HHP death kinetics of Escherichia coli strain ATCC 25922 in frozen and unfrozen nutrient broth. Pressure treatment at $400 \mathrm{MPa}$ with zero holding time or a pressure treatment at $350 \mathrm{MPa}$ for 1 min inactivated E. coli strain ATCC 25922 in frozen $\left(-20^{\circ} \mathrm{C}\right)$ nutrient broth by more than $6 \log \mathrm{CFU} \cdot \mathrm{ml}^{-1} \mathrm{cycles}$, whereas the inactivation in unfrozen nutrient broth was less than $1.0 \mathrm{log}$ of CFU $\cdot \mathrm{ml}^{-1}$. The same research group, (Zhu, Wang, Ramaswamy, 
\& Yu, 2017) studied the effect of HHP on phase transition of frozen carrot juice and the inactivation kinetics of $E$. coli ATCC 25922. D values of $E$. coli in frozen carrot juice (at $-20^{\circ} \mathrm{C}$ ) reported to be between 2.62 and $2.12 \mathrm{~min}$ in the range of $300-400 \mathrm{MPa}$, whereas unfrozen carrot juice had significantly higher $\mathrm{D}$ values of 28.5 and $5.32 \mathrm{~min}$ for the same pressure range. The authors concluded that the combination of frozen state, phase transition status and pressure level were likely to be responsible for the higher inactivation of $E$. coli in frozen carrot juice.

Shiba and Furushita (2017) created a thermal buffer zone around the plastic bags of bacterial suspensions in $1 \%$ skim milk by using two polytetrafluoroethylene plates. The bacterial suspensions held between the polytetrafluoroethylene plates were brought to $-50^{\circ} \mathrm{C}$ before a $20 \mathrm{~min}$ pressure treatment at $200 \mathrm{MPa}$ and $4{ }^{\circ} \mathrm{C}$, which resulted in a reduction of $8 \log$ cycles of $E$. coli strain ATCC 10798. The authors suggested that a homogeneous temperature within the sample achieved by an initial temperature that was low enough to keep the sample temperature below the melting point during compression, and the completion of melting within the holding time were necessary to take the advantage of combined subzero temperature and high pressure during pressure-assisted thawing.

Ekonomou, Bulut, Karatzas, and Boziaris (2020) investigated the possibility of using a very low pressure in combination with liquid smoke and freezing to eliminate Listeria monocytogenes $10403 \mathrm{~S}$ in trout samples. Treatment with liquid smoke followed by freezing prior to pressurization at 200 $\mathrm{MPa}$ for $15 \mathrm{~min}$ reduced the number of $L$. monocytogenes by more than $5-\log \mathrm{CFU} \cdot \mathrm{ml}^{-1}$.

From the limited number of studies as summarized above, it is clear that microorganisms could be efficiently inactivated at relatively low pressures when the food material is frozen prior to pressure a treatment which could take place at subzero or above zero temperatures. The significant antimicrobial effect of this type of treatment should be further studied as it is able to easily eliminate spoilage and pathogenic organisms from foods while offering major advantages to the food industry. Subzero HHP processing is relatively new field and although there are some explanations for the increased microbial inactivation, there is no a complete understanding of the mode of action. A better understanding of the mechanism behind this could be utilized for reduction of the treatment intensity, which in turn could significantly reduce the cost of HHP equipment manufacturing and could lead to wider adoption of the technology by the food industry.

Escherichia coli is a rod-shaped Gram-negative facultative anaerobe bacterium that normally resides in the intestine of humans and other animals. A few strains are pathogenic some of which cause genitourinary infections and some are responsible for traveler's diarrhea (Neidhardt \& Kushner, 2017). 
Various strains of $E$. coli have been widely used as a test organisms in life sciences including in some of the studies on nonthermal technologies for fruit and vegetable juices (Bevilacqua, et al., 2018). Among the pathogenic strains, E. coli $\mathrm{O} 157: \mathrm{H7}$ received a great deal of attention due to its link to food borne illness outbreaks.

FDA guideline for the fruit juice industry (FDA, 2004) states that a 5 -log reduction must be targeted for the pertinent pathogen which is the most resistant microorganism of public health concern that may occur in the fruit juice. FDA also states that the pertinent pathogen may vary with the type of juice and the type of treatment used, though typically it could be Salmonella or Escherichia coli 0157:H7 (FDA, 2001). FDA does not have a definitive suggestion as a test organism for HHP processing however, E. coli $\mathrm{O} 157: \mathrm{H7}$ is the main microorganism of concern that should be studied for process development, challenge work and process validation (Institute of Food Technologists, 2000). However, it was shown that E. coli 0157:H7 (ATCC 700728) in orange juice was more sensitive to pressure compared to E. coli K12 (Torres, González-M, Klotz, \& Rodrigo, 2016), suggesting that $E$. coli K12 could be a more suitable strain for HHP studies.

In this study, we used E. coli K12 as a test organism. Samples were prepared by inoculation of $E$. coli $\mathrm{K} 12$ in phosphate buffered saline (PBS, pH 7.1) and then they were pressurised at either $4{ }^{\circ} \mathrm{C}$ (unfrozen), or at $-24^{\circ} \mathrm{C}$ and $-80^{\circ} \mathrm{C}$ (frozen). Using PBS as a model liquid let us to investigate the bacterial morphology by scanning electron microscopy and determination of the amount of nucleic acids in PBS by NanoDrop spectroscopy, which helped us to better understand the mechanism of bacterial inactivation by HHP under frozen state. In order to test the effectiveness of HHP in frozen state in a real liquid food with different $\mathrm{pH}$, orange juice was inoculated with the same strain of $E$. coli and pressurized in frozen and unfrozen state.

\section{MATERIALS AND METHODS}

\subsection{Bacterial strain and growth conditions}

A pure culture of E. coli strain K12 was obtained from the culture collection of the Department of Food and Nutritional Sciences, University of Reading. The stock culture was kept at $-80^{\circ} \mathrm{C}$ in $15 \%$ (v/v) glycerol and prior to experiments a sample was transferred onto LB Agar (Lab M limited, UK) agar plates which were incubated at $37^{\circ} \mathrm{C}$ overnight. The inoculum was prepared by transferring three isolated colonies from the latter plates into $200 \mathrm{ml}$ sterile LB Broth (Lab M limited, UK) in 500 $\mathrm{ml}$ sterile flasks and incubated at $37^{\circ} \mathrm{C}$ for $18 \mathrm{~h}$ to give approximately $10^{9} \mathrm{CFU} \cdot \mathrm{ml}^{-1}$ at stationary phase. Subsequently, cells were harvested by centrifugation, (7000 $\times \mathrm{g}$ for $5 \mathrm{~min})$ and washed twice 
in sterile phosphate buffered saline solution (PBS, Oxoid, Basingstoke, UK) before they were resuspended in sterile PBS ( $\mathrm{pH} 7.1$ ) at a concentration of approximately $10^{9} \mathrm{CFU} \cdot \mathrm{ml}^{-1}$ (stock suspension).

\subsection{Preparation of inoculated PBS samples}

By using a heat sealer, small plastic bags were prepared out of sterile stomacher bags. Subsequently, $12 \pm 1 \mathrm{ml}$ of $E$. coli strain $\mathrm{K} 12$ stock suspension were transferred with a sterile syringe in the bags which were sealed and placed into a larger sterile stomacher bags by using a vacuum sealer to prevent contamination of the pressurization medium in case of rupture during pressurization. Samples were then stored under 3 different conditions overnight as follows: i) at $4^{\circ} \mathrm{C}$ in a laboratory refrigerator (Labocold, Chineham, UK), ii) at $-24^{\circ} \mathrm{C}$ in a laboratory freezer (Labcold, Chineham, UK) and iii) at $-80^{\circ} \mathrm{C}$ in a laboratory freezer (New Brunswick U57OHEF, UK).

\subsection{Preparation of orange juice samples}

In order to compare the inactivation of $E$. coli K12 in PBS with a real food system, experiments were conducted in orange juice inoculated with E. coli K12. For this purpose, oranges bought from a local supermarket were sprayed with \%70 (v/v) alcohol and then wiped with paper towel after $1 \mathrm{~min}$. Then, oranges were cut in half with a sterile knife by hand using gloves sanitized with $\% 70(\mathrm{v} / \mathrm{v})$. Half oranges were squeezed manually and filtered through a sterilised sieve ( $315 \mu \mathrm{m}$ aperture) into a sterile bowl. Samples of orange juice $(3 \times 5 \mathrm{ml})$ were taken for microbiological analysis before it was inoculated with E. coli $\mathrm{K} 12$ at a level of about $10^{9} \mathrm{CFU} \cdot \mathrm{ml}^{-1}$. For inoculation of orange juice, stock suspension of $E$. coli $\mathrm{K} 12$ was centrifuged at $7000 \times \mathrm{g}$ and the supernatant was discarded to eliminate the buffering potential of PBS. About $30 \mathrm{ml}$ orange juice was added into a centrifuge tube and then vortexed for $1 \mathrm{~min}$ to disperse $E$. coli cells in the orange juice. The tubes were then poured into a bowl holding orange juice and mixed for $1 \mathrm{~min}$ with a sterile spatula. After inoculation, the $\mathrm{pH}$ of orange juice was adjusted to $3.2,4.5$ and 5.8 by either adding sterile citric acid $(0.2 \mathrm{M})$ or sodium hydroxide $(1.0 \mathrm{M})$ solution. The orange juice was then packed into sterile stomacher bags $(12 \pm 1 \mathrm{ml})$ by using a heat sealer. The samples were then packed for the second time by using a vacuum sealer. Half of the samples were kept in a walk-in fridge operating at $4 \pm 1^{\circ} \mathrm{C}$ and the rest were kept at $-80^{\circ} \mathrm{C}$ in a freezer.

\subsection{HHP treatment}

A HHP system (Stansted Fluid Power Products Ltd., Harlow, UK) having a $16 \mathrm{~mm}$ internal diameter and $55 \mathrm{ml}$ working volume was used to treat the samples. Alcohol ( $80 \% \mathrm{v} / \mathrm{v})$ mixed with castor oil $(20 \% \mathrm{v} / \mathrm{v})$ 
was used as the pressure transmitting medium (PTM) and the temperature of the medium inside the pressure chamber was controlled with a water jacket surrounding the pressure vessel connected to a cooling circulator (Grant LTD6G, UK). All pressurization experiments were carried out at $4 \pm 1{ }^{\circ} \mathrm{C}$, while temperature was measured by a K-type thermocouple mounted to the head of the machine and being in contact with the pressurization liquid to monitor the internal temperature in the pressure chamber. Samples were quickly placed in the pressure chamber which was previously brought to test temperature $\left(4 \pm 1^{\circ} \mathrm{C}\right)$. The time to remove the samples from the fridge or freezer and the start of pressurization was less than $30 \mathrm{~s}$. After a pre-set pressurization time, the pressure was automatically released in less than $5 \mathrm{~s}$ to atmospheric pressure. The temperature of PTM was recorded by a data logger during the experiments. After pressure treatment, all the samples were taken to a refrigerator operating at $4 \pm 1{ }^{\circ} \mathrm{C}$ until the time of analysis on the same day.

\subsection{Enumeration of microorganisms}

By using sterile PBS ( $\mathrm{pH} 7.1$ ), dilutions were prepared from control and pressure-treated samples. Dilutions were plated on LB agar by the spot plate method in duplicate and the average values from two counts were used for calculations. The plates were then incubated at $37^{\circ} \mathrm{C}$ for $24 \mathrm{~h}$ for control samples and $48 \mathrm{~h}$ for pressurized samples before counting the colonies. Microbial reduction was expressed in terms of logarithmic reduction corresponding to the difference between the logarithms of the initial number of microorganism before pressure treatment and that of the number of microorganisms surviving after pressure treatment.

\subsection{Scanning Electron Microscopy (SEM) imaging}

Suspensions ( $200 \mu \mathrm{l})$ from each sample were pipetted onto poly-L-lysine coated glass coverslips for $15 \mathrm{~min}$. The adhered bacteria were fixed with a solution of $2 \%$ paraformaldehyde and $2.5 \%$ glutaraldehyde $(\mathrm{pH} 7.0)$ for $15 \mathrm{~min}$ and subsequently washed with sterile distilled water. The samples were then dehydrated through a series of ethanol solutions (30\%, $50 \%, 70 \%, 80 \%, 90 \%$ and $100 \%)$ prepared with deionised water. Then the samples were dried in a critical point dryer (Balzers 030 Critical Point Dryer) and coated with a thin layer of gold (Edwards S150B Sputter Coater). The scanning electron micrographs were obtained using a FEI Quanta 600 FEG SEM equipped with the xTm user interface (version 2.4).

\subsection{Determination of DNA and RNA concentration in PBS}

A NanoDrop ${ }^{\text {TM }} 1000$ Spectrophotometer (Thermo Fisher Scientific, ND-1000) controlled by ND-1000 v.3.8.1 software was used for determination of DNA and RNA concentration in PBS. For this purpose, 
following pressure treatment, bacterial suspensions were centrifuged at $13000 \mathrm{rpm}$ (Thermo Fisher Scientific, Pico 17) for $10 \mathrm{~min}$ at room temperature. The supernatant was separated and $2 \mu \mathrm{l}$ was used for the determination of DNA and RNA spectrophotometrically at $260 \mathrm{~nm}$ as described by (Desjardins \& Conklin, 2010). Unprocessed samples that were kept at $4{ }^{\circ} \mathrm{C}$ and $-80{ }^{\circ} \mathrm{C}$ overnight were used as controls. Frozen samples were thawed before measurements. Three readings were taken from each of the samples and the averages of the readings were used for plotting the graph.

\subsection{Statistical analysis}

The surface response experimental was designed and analysed by employing Design-Expert v.10 Software (Stat-Ease Inc. Minneapolis, USA). For experiments with PBS inoculated with E. coli K12, a rotatable central composite design ( $\alpha=1.4142)$ with 3 replicates of central point was used, where variable parameters were pressure (159 - $441 \mathrm{MPa}$ ) and time (1-11 min). The experimental design with randomized run order and the resulting response variables are given in Table 2. Standard errors were determined by repletion $(n=3)$ of the central point of the design ( $300 \mathrm{MPa}, 5 \mathrm{~min}$ ). All data were subjected to Analysis of Variance (ANOVA). Sequential model sum of squares and lack of fit tests were conducted for determination of best model (linear, quadratic or two factor interaction) for each response variable. Level of significance was set for $p<.05$ and the significance of each response variable was assessed by F-test.

For the experiments with orange juice inoculated with E. coli, a factorial design was chosen where 3 levels of $\mathrm{pH}(3.2,4.5,5.8)$ and 3 levels of time $(5,10,15 \mathrm{~min})$ were tested at $250 \mathrm{MPa}$ with 3 replicates. Data were plotted by OriginPro v. 2019 (OriginLab Corporation, Northampton, MA, USA). Microsoft ${ }^{\circledast}$ Excel $^{\circledast} 2016$ (Microsoft Corporation, USA) was used for calculation of standard deviations (StDev).

\subsection{Validations}

Based on the models produced by RSM, the optimization function of Design-Expert v.11 Software predicted that a 9 min pressure treatment of frozen PBS samples $\left(-24^{\circ} \mathrm{C}\right.$ or $\left.-80^{\circ} \mathrm{C}\right)$ at 180 or 250 $\mathrm{MPa}$ could result in more than 5 log reduction in number of $E$. coli K12. Therefore, validations were carried out at 180 and $250 \mathrm{MPa}$ as the aim of the study was to use the lowest possible pressures that could result in about 5 log reduction in number of $E$. coli $\mathrm{K} 12$. 


\section{RESULTS AND DISCUSSIONS}

217

218

219

220

221

222

223

224

225

226

227

228

229

230

231

232

233

\subsection{Inactivation of $E$. coli $\mathrm{K} 12$ in PBS and mechanism of inactivation}

A limited number of studies as well as our work presented here show that microbial inactivation could be significantly increased when pressure is applied on a frozen material. However, lack of evidence on mechanism behind such an increased inactivation hinders better exploitation of this technology. Therefore, in the first part of this study we focused on understanding the mechanisms behind enhanced microbial inactivation in HHP treated frozen PBS.

\subsubsection{Effect of freezing on E. coli K12 in PBS}

Freezing on its own can inflict damage on microbial cells. Therefore, it was necessary to understand the effect of freezing and thawing on E. coli K12 under atmospheric conditions. Our results showed that freezing at $-24^{\circ} \mathrm{C}$ and $-80^{\circ} \mathrm{C}$ overnight followed by thawing at room temperature resulted in $1.73 \pm 0.12$ and $1.49 \pm 0.07 \log$ reduction, respectively. Freezing is known to cause inactivation of microorganisms and the extent of the damage to bacterial cells depends on mainly the food matrix and the freezing speed (temperature). Damage to microbial cell due to atmospheric freezing could be due to ice crystal formation and growth within the cytoplasm that could result in a decrease in $\mathrm{pH}$ (due to freeze concentration), which eventually could cause protein (enzyme) denaturation and death of microbial cells. It was shown that slow freezing caused more death of $E$. coli cells compared to rapid freezing (Souzu, 1980).

\subsubsection{Temperature profile during pressurization}

Temperature of PTM was measured during the pressurization. As seen in Figure 1, in a typical experiment the temperature of the pressure chamber measured through PTM was $4.5^{\circ} \mathrm{C}$ before the insertion of a frozen sample. The temperature of PTM dropped to about $1.4{ }^{\circ} \mathrm{C}$, before it started to increase by the onset of pressurization. At around $315 \mathrm{MPa}$, there was about $55 \mathrm{MPa}$ pressure drop accompanied by a $2.5^{\circ} \mathrm{C}$ temperature drop. This pressure drop was systematic but the magnitude of it varied depending on the temperature of the samples $\left(-24^{\circ} \mathrm{C}\right.$ or $\left.-80^{\circ} \mathrm{C}\right)$ and the set maximum pressure. The drop was instantaneous and took place during the pressure build up period for the experiments that employed pressures above $300 \mathrm{MPa}$. For the experiments that was carried out at lower pressures, the magnitude of the pressure drop was less and took place during the pressure holding period. 
In a typical experiment, the temperature of the PTM gradually approached to about $3^{\circ} \mathrm{C}$ after $10 \mathrm{~min}$ of pressurization. Upon releasing the pressure, the temperature instantaneously dropped to $-10.6^{\circ} \mathrm{C}$ due to expansion. The samples were removed from the pressure chamber within 10 seconds of pressure release. The samples removed from the pressure chamber were either melted or partially frozen, depending on the initial temperature of the samples $\left(-24\right.$ or $\left.-80^{\circ} \mathrm{C}\right)$, intensity of pressure and pressurization time. As a general observation, for pressure treatments that were less than $5 \mathrm{~min}$, the samples were not completely melted. For higher pressure intensities and/or longer treatment times the samples were in liquid state when they were removed from the pressure chamber.

\subsubsection{Effect of pressure and pressurization time on microbial inactivation}

254

In order to understand the impact of pressure and pressurization time on the inactivation of $E$. coli in PBS, we constructed a response surface for log reductions of $E$. coli as a function of pressure and pressurization time for the samples that were kept in a refrigerator overnight $\left(4^{\circ} \mathrm{C}\right)$, frozen at $-24^{\circ} \mathrm{C}$ and $-80^{\circ} \mathrm{C}$ for overnight (Figure 2).

Bacterial inactivation increased to a maximum of $1.83 \mathrm{log} \mathrm{CFU} \cdot \mathrm{ml}^{-1}$ at the most severe pressure conditions (400 MPa, $9 \mathrm{~min}$ ) for the samples that were kept in a refrigerator at $4{ }^{\circ} \mathrm{C}$ (Figure 2a). Log reduction CFU $\cdot \mathrm{ml}^{-1}$ was strongly correlated with pressure $(p=.0011)$, time $(p<.0001)$ and interaction of pressure and time $(p=.0198)$. The response surface (model $\left.r^{2}=0.94, p=.002\right)$ produced by two factor interaction model had the following equation of surface:

Where, $P$ is pressure in MPa and $t$ is time in min.

Overnight freezing at $-24^{\circ} \mathrm{C}$ and $-80^{\circ} \mathrm{C}$ prior to pressurization enhanced bacterial inactivation significantly as seen in Figure $2 b$ and Figure $2 c$. For frozen samples the time and pressure interaction terms were not significant $(p>.05)$ and the response surfaces were produced by linear models. Response surface for the samples frozen at $-24{ }^{\circ} \mathrm{C}$ (model $r^{2}=0.93, p<.0001$ ) produced the following equation where pressure $(p=.0089)$ and time $(p<.0001)$ were the significant terms.

271 The linear response surface for the samples frozen at $-80^{\circ} \mathrm{C}$ (model $r^{2}=0.93, p<.0001$ ) produced the

272 following equation where pressure $(p=.0005)$ and time $(p<.0001)$ were the significant terms.

273 Log reduction $\left(c f u \cdot \mathrm{ml}^{-1}\right)=0.861+8.55 \times 10^{-3} \times P+0.334 \times t$ 
Freezing PBS suspension of $E$. coli K12 prior to HHP treatment increased microbial inactivation remarkably. For example, after a 9 min pressure treatment at $400 \mathrm{MPa}$ and $4{ }^{\circ} \mathrm{C}$, a 6.83 log reduction of CFU $\cdot \mathrm{ml}^{-1}$ was obtained in frozen PBS suspension $\left(-80^{\circ} \mathrm{C}\right)$ while, only 1.83 the log reduction of $\mathrm{CFU} \cdot \mathrm{ml}^{-1}$ was observed in unfrozen PBS suspension $\left(4^{\circ} \mathrm{C}\right)$. More interestingly, significant levels of inactivation were observed in frozen PBS samples even after a very brief exposure to pressure. After a $1 \mathrm{~s}$ pressurization at $300 \mathrm{MPa}$, the log reductions in $\mathrm{CFU} \cdot \mathrm{ml}^{-1}$ of $E$. coli were 2.60 and 3.52 for the samples frozen at -24 and $-80^{\circ} \mathrm{C}$, respectively. On the other hand, inactivation in unfrozen samples $\left(4^{\circ} \mathrm{C}\right)$ was insignificant $\left(0.01 \log \mathrm{CFU} \cdot \mathrm{ml}^{-1}\right)$. Similar observations were reported previously by Su, et al. (2014) who showed more than $6 \mathrm{log}$ reduction in CFU $\cdot \mathrm{ml}^{-1}$ for $E$. coli ATCC 25922 in frozen nutrient broth after $1 \mathrm{~min}$ at $350 \mathrm{MPa}$ and room temperature. In previous work (Bulut, 2014b) we reported a $3.8 \mathrm{log}$ reduction in CFU. $\mathrm{ml}^{-1}$ of $E$. coli ATCC 25922 in frozen milk after 1 min exposure to $300 \mathrm{MPa}$ at $-3{ }^{\circ} \mathrm{C}$.

Increased microbial inactivation as a result of freezing the samples prior to pressure treatment could be explained mainly by the mechanical stress associated with the solid-solid phase transitions of ice I to other ice polymorphs (Luscher, et al., 2004). As the density of ice-l $\left(0.92 \mathrm{~g} \cdot \mathrm{cm}^{-3}\right)$ is lower than the density of Ice-II $\left(1.16 \mathrm{~g} \cdot \mathrm{cm}^{-3}\right)$, ice-III $\left(1.16 \mathrm{~g} \cdot \mathrm{cm}^{-3}\right)$ and ice-V $\left(1.24 \mathrm{~g} \cdot \mathrm{cm}^{-3}\right)$, a phase change from ice-I to other forms of ice results in a volume decrease (Chaplin, 2018). In our experiments we observed this volume decrease at about $315 \mathrm{MPa}$ where a sudden pressure drop of about $55 \mathrm{MPa}$ took place accompanied by a $4-5{ }^{\circ} \mathrm{C}$ temperature drop (Figure 1 ) as a result of the endothermic nature of transitions from ice-I to other forms of ice.

The temperature drop (to about -12 to $-4{ }^{\circ} \mathrm{C}$ ) upon release of the pressure could cause pressure shift freezing, which could contribute to increased bacterial inactivation as suggested by some authors (Alizadeh, Chapleau, de Lamballerie, \& Le-Bail, 2007; Picart, Dumay, Guiraud, \& Cheftel, 2004; Picart, Dumay, Guiraud, \& Cheftel, 2005; Volkert, Ananta, Luscher, \& Knorr, 2008). In our experiments, only the frozen samples that were exposed to moderate pressures (100-300 MPa) for short periods of time $(<5 \mathrm{~min})$ were partially frozen by the end of the pressure cycle, which infers that either the samples were not melted thoroughly during the pressure cycle and/or pressure shift freezing took place. There was no evidence of pressure shift freezing in pressure treated unfrozen samples $\left(4^{\circ} \mathrm{C}\right)$ when they were removed from the pressure chamber right after the pressure release. This was probably due to a very short time exposure (less than $10 \mathrm{~s}$ ) to low temperatures $\left(-8\right.$ to $\left.-4{ }^{\circ} \mathrm{C}\right)$ after releasing of the pressure. 
Our results show that when samples were frozen at $-80{ }^{\circ} \mathrm{C}$ before the pressurization, a higher microbial inactivation was observed compared to samples that were frozen at $-24{ }^{\circ} \mathrm{C}$ (Figure 2). This could be explained by increased rigidity of bacterial cell wall at $-80^{\circ} \mathrm{C}$ and higher number of solid to solid phase transitions taking place as per the water phase diagram under pressure (Chaplin, 2018; LeBail, Chevalier, Mussa, \& Ghoul, 2002; Luscher, et al., 2004; Zhu, et al., 2017).

\subsubsection{Validation of models obtained by response surface methodology}

As shown in Table 1, the validation experiments showed that the predicted values by the models presented by Eq. 1-3 were in reasonable agreement with the actual results.

\subsubsection{Effect of freezing and pressure on morphology of $E$. coli K12 cells}

The freeze damage that caused inactivation of $E$. coli $\mathrm{K} 12$ as detected by microbiological counts was visible in SEM images. As seen in Figure $3 \mathrm{~b}$ and $3 \mathrm{c}$, thawing after freezing at $-24^{\circ} \mathrm{C}$ and $-80^{\circ} \mathrm{C}$ resulted in bacterial morphology changes which could be explained by the effects of freezing and thawing.

Major disintegration of $E$. coli cell wall structure was observed in samples that were frozen before the pressurization (Figure $3 e$ and 3f), whereas there were no signs of damage to bacterial cell wall in unfrozen samples pressurized under the same conditions (Figure 3d). Zhou, Zhang, Wang, Dong, Hu, and Zhang (2019) also did not observe cell disintegration or a significant change in morphology of Escherichia coli 0157:H7 in physiological saline after a 450 MPa pressure treatment at room temperature. Therefore, under normal conditions, cell membrane damage is not a major contributor in the bacterial inactivation process as suggested by Rivalain, Roquain, and Demazeau (2010). On the contrary, cell membrane damage appears to be the major cause of bacterial inactivation in pressurized frozen samples. To the best of our knowledge this is the first time such clear SEM micrographs show the extent of damage to bacterial cell walls in frozen samples after HHP.

\subsubsection{DNA and RNA leakage from $E$. coli K12 cells after pressure treatments}

As seen in SEM micrographs, significant disruption to bacterial cell membrane was observed in samples that were frozen before pressure treatment. In order to verify possible leakage of intracellular material DNA and RNA of treated and non-treated cells was determined by NanoDrop

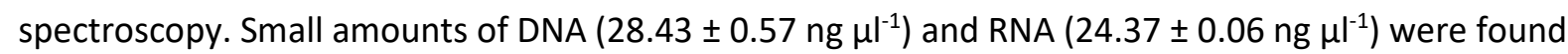
in control samples (Figure 4). DNA and RNA concentrations in frozen and thawed samples were $181.37 \pm 3.07$ and $151.40 \pm 1.93 \mathrm{ng}^{-1} \mathrm{l}^{-1}$ respectively. After pressurization of frozen samples, DNA and 
RNA concentrations were $537.73 \pm 7.60$ and $450.60 \pm 6.56 \mathrm{ng} \mathrm{\mu l}^{-1}$ respectively. Significantly increased levels of DNA and RNA in pressure-treated frozen PBS samples suggest loss of cell wall integrity, which was also evident in SEM images providing strong evidence that membrane damage is the major cause of bacterial inactivation during HHP treatment of frozen PBS suspension.

\subsection{Inactivation of $E$. coli $\mathrm{K} 12$ in orange juice}

In order to see if this technique could be applied in a real food system, orange juice was employed as a test medium. Orange and other fruit juices are some of the products where HHP is commonly used. Currently, beverages are the fastest growing segment of food products among the HHP processed foods, worldwide (2020).

\subsubsection{Microbial load of orange juice}

No microbial growth was observed on LB agar for the samples of orange juice before inoculation with E. coli (min detection level $<10 \mathrm{CFU} \cdot \mathrm{ml}^{-1}$ ) indicating absence of $E$. coli and other organisms. After inoculation with $E$. coli $\mathrm{K} 12$ and overnight storage at $4{ }^{\circ} \mathrm{C}$, the number of $E$. coli in unpressurized control samples ranged between $2.2 \times 10^{8} \mathrm{CFU} \cdot \mathrm{ml}^{-1}$ and $5.3 \times 10^{8} \mathrm{CFU} \cdot \mathrm{ml}^{-1}$ for the samples prepared on different days. The $\mathrm{pH}$ of orange juice did not have a significant effect on counts of $E$. coli during the overnight storage at $4{ }^{\circ} \mathrm{C}$ and the average counts of orange juice with $\mathrm{pH} 3.2,4.5$ and 5.8 was 8.5 $\pm 0.04 \log \mathrm{CFU} \cdot \mathrm{ml}^{-1}(\mathrm{n}=9)$.

\subsubsection{Effect of freezing on E. coli $\mathrm{K} 12$}

Freezing at $-80^{\circ} \mathrm{C}$ overnight followed by thawing at room temperature did not result in significant change in the numbers of $E$. coli $\mathrm{K} 12$ in orange juice at all the $\mathrm{pH}$ values and the average of counts were $8.51 \pm 0.03 \mathrm{CFU} \cdot \mathrm{ml}^{-1}$. This could be explained by the protective effect of soluble solids and fibres in orange juice. Although the proximate composition analysis of orange juice used for our experiments was not performed, it has been reported that orange juice contains about $120.19 \mathrm{~g} \cdot \mathrm{L}^{-1}$ total sugar (Kelebek, Selli, Canbas, \& Cabaroglu, 2009).

\subsubsection{Effect of pressurization time and $\mathrm{pH}$ on inactivation of E. coli $\mathrm{K} 12$}

In this work we also assessed the inactivation of E. coli K12 in orange juice as a function of $\mathrm{pH}$ and pressurisation time for unfrozen $\left(4^{\circ} \mathrm{C}\right.$; Figure $\left.5 \mathrm{a}\right)$ and frozen $\left(-80^{\circ} \mathrm{C}\right.$; Figure $\left.5 \mathrm{~b}\right)$ samples at $250 \mathrm{MPa}$, as preliminary experiments showed that a-5 log reduction is possible at this pressure.

Pressure treatments of unfrozen orange juice samples with $\mathrm{pH}$ values of 4.5 and 5.8 resulted in insignificant reductions of less than $0.42 \log \mathrm{CFU} \cdot \mathrm{ml}^{-1}$ in number of $E$. coli at all pressurizations times. 
On the other hand, up to $3.84 \pm 0.33 \mathrm{log}$ reduction of $\mathrm{CFU} \cdot \mathrm{ml}^{-1}$ was obtained in unfrozen orange juice having a pH of 3.2 after a 15 min pressurization. Enhanced inactivation at lower $\mathrm{pH}$ could be explained by increased antimicrobial activity of organic acids present in orange juice. Kelebek, et al. (2009) reported that orange juice contained $12.66 \mathrm{~g} \cdot \mathrm{L}^{-1}$ citric acid, $0.49 \mathrm{~g} \cdot \mathrm{L}^{-1}$ ascorbic acid, $1.06 \mathrm{~g} \cdot \mathrm{L}^{-1}$ malic acid, $4.28 \mathrm{mg} \cdot \mathrm{L}^{-1}$ hydroxybenzoic acids (gallic and protocatechuic acid) and $60.38 \mathrm{mg} \cdot \mathrm{L}^{-1}$ hydroxycinnamic acids (caffeic, chlorogenic, p-Coumaric, ferulic and sinapic acid). It should be noted that, we used citric acid which is naturally present in orange juice to lower the $\mathrm{pH}$ of orange juice used in our experiments. Weak organic acids are most effective on microorganisms in their undissociated form (Erkmen \& Bozoglu, 2016) as they can pass through the membrane and acidify the cytoplasm of the microbial cells. Organic acids are more effective at low pH values, where solutions have increased concentrations of undissociated acids (Lambert \& Stratford, 1999). Smelt (1998) suggested that undissociated organic acid molecules could be more active under pressure. Alpas, Kalchayanand, Bozoglu, and Ray (2000) demonstrated that inactivation of E. coli O157:H7 933 in $1 \%$ peptone water following a pressurization at $345 \mathrm{MPa}$ for 5 min increased from 1.86 to $3.82 \mathrm{log}$ reduction of $\mathrm{CFU} \cdot \mathrm{ml}^{-1}$ when the $\mathrm{pH}$ of the medium was reduced from 6.5 to 4.5 by addition of citric acid.

As seen in Figure 5b, inactivation of E. coli K12 in orange juice increased significantly when the samples were frozen before pressure treatment and this increase was more pronounced for the samples having $\mathrm{pH} 4.5$ and 5.8. For example, freezing orange juice with $\mathrm{pH} 3.2$ increased the bacterial inactivation from 3.84 (unfrozen) to $4.88 \mathrm{log} \mathrm{CFU} \cdot \mathrm{ml}^{-1}$ after a $15 \mathrm{~min}$ pressure treatment. In comparison, when the samples were frozen before the same pressure treatment, bacterial inactivation increased from 0.35 (unfrozen) to $4.22 \log \mathrm{CFU} \cdot \mathrm{ml}^{-1}$ for samples with $\mathrm{pH} 4.5$, and from 0.42 (unfrozen) to $4.41 \mathrm{log} \mathrm{CFU} \cdot \mathrm{ml}^{-1}$ for the samples with $\mathrm{pH}$ 5.8. About $4 \log$ unit increase in bacterial inactivation as a result of freezing orange juice with $\mathrm{pH}$ of 4.5 and 5.8 before pressurization, indicates that the main mechanism of inactivation in frozen orange juice is partly different from that in unfrozen orange juice where log reduction remained below $0.42 \log \mathrm{CFU} \cdot \mathrm{ml}^{-1}$. Therefore, the main mechanism of bacterial inactivation in frozen orange juice is most likely to be due to disintegration of cell membrane as in the case of frozen BPS.

The results indicate that the $\mathrm{pH}$ is a less critical factor for inactivation of $E$. coli in orange juice by HHP when samples are frozen. This observation could be important, as freezing of liquid foods (fruit and vegetable juices) before pressure treatment may remove the necessity of a strict control and/or 
adjustment of the $\mathrm{pH}$ of the juices, provided that other measures (hurdles) are in place to prevent the growth of spore forming pathogenic bacteria.

\subsubsection{Effect of temperature of pressurization and $\mathrm{pH}$ on inactivation of $E$. coli K12}

In order to maximize the bactericidal potential of organic acids in orange juice during the pressurization process, further pressurization experiments were conducted where orange juice samples containing E. coli $\mathrm{K} 12$ were frozen at $-80^{\circ} \mathrm{C}$ and then pressurized at $20^{\circ} \mathrm{C}$ (temperature of PTM). Figure 6 shows inactivation of $E$. coli $\mathrm{K} 12$ in frozen orange juice samples after pressurization at $4{ }^{\circ} \mathrm{C}$ and $20^{\circ} \mathrm{C}$. As seen in the figure, pressurization of frozen $\left(-80^{\circ} \mathrm{C}\right)$ orange juice samples at $20^{\circ} \mathrm{C}$ resulted in similar inactivation of E. coli, compared to pressure treatment at $4{ }^{\circ} \mathrm{C}$.

The inactivation of $E$. coli in frozen orange juice having $\mathrm{pH}$ of 3.2 was slightly higher at $20^{\circ} \mathrm{C}(5.0 \mathrm{log}$ reduction of $\left.\mathrm{CFU} \cdot \mathrm{ml}^{-1}\right)$, compared to $4{ }^{\circ} \mathrm{C}\left(4.6 \mathrm{log}\right.$ reduction $\left.\mathrm{CFU} \cdot \mathrm{ml}^{-1}\right)$. This could be explained by the fact that compared to pressurization at $4{ }^{\circ} \mathrm{C}$, the sample melts faster under pressure at $20^{\circ} \mathrm{C}$, meaning that it will remain for longer in the liquid phase under the latter temperature. During a typical pressurization of frozen samples at $20^{\circ} \mathrm{C}$, the temperature measured through PTM increases to a max of $32.4^{\circ} \mathrm{C}$ within $50 \mathrm{~s}$ of pressure build up period. The temperature gradually drops to $21.7^{\circ} \mathrm{C}$ by the end of $10 \mathrm{~min}$ pressurization time and then instantly drops to $12.5^{\circ} \mathrm{C}$ upon releasing the pressure.

In order for organic acids to diffuse through the cell membrane a liquid phase is required. Following the solid-solid phase transitions and melting, the sample remains for longer periods of time in liquid phase at a higher temperature $\left(20^{\circ} \mathrm{C}\right)$. As a result, organic acids in low $\mathrm{pH}$ orange juice could more effectively interact with $E$. coli cells which is further enhanced by the pressure. This observation could have important implications in industrial applications, as it may not be necessary to cool the pressure chamber and PTM to a low temperature of $4{ }^{\circ} \mathrm{C}$, (orange juice must frozen before the pressurization) in order to obtain required microbial inactivation, which in turn could reduce the running costs of HHP processing.

Achievement of a 5-log reduction for a pressure resistant E. coli K12 at a very low pressure of 250 $\mathrm{MPa}$, compared to the commonly used commercially $600 \mathrm{MPa}$, is significant. To put things in perspective from an economic point of view, a specific reduction in the required pressure would not result in a proportional reduction in manufacturing cost of the equipment (informal discussions with equipment manufacturers). This is due to the fact that the components and materials cost, as well as the complexity of construction technologies increase significantly, as the operation pressure 
increases. Another advantage of HHP equipment operating at lower pressures is that, it easily allows construction of equipment with larger volumes. This is important as one of the main disadvantages of HHP equipment is their limited capacity (compared to conventional processes).

In terms of the freezing cost prior to HHP, it could be stated that most foods processed by HHP are required to be chilled to refrigeration temperatures, which requires energy expenditure and time. Thus, while cooling the products after the pressure treatment, the quality and shelf life of the food could be adversely affected. In case of pressurization of orange juice in frozen state, the cost of freezing could be justified as the orange juice comes out from HHP at near zero temperatures and it could to be shipped without any delay for cooling. Furthermore, the freezing cost per unit is very low as the products remain for only a few hours at this temperature. It is worth mentioning that in some cases increasing the pressure beyond a certain point could cause irreversible damage to some biological molecules such as proteins and this could impact the functionality of end product. Other adverse effects of HHP, such as undesirable changes in colour and functionality of foods and food ingredients could also be minimised by this approach.

\section{Conclusions}

Clear evidence by SEM micrographs and measurement of nucleic acids concentrations in PBS revealed that the significantly increased microbial inactivation in pressure treated frozen PBS is mainly due to physical damage of $E$. coli cells. Further studies with orange juice, showed that this remarkable bacterial inactivation in pressure treated frozen orange juice was not significantly $\mathrm{pH}$ dependent, whereas the limited inactivation in unfrozen orange juice was strongly pH dependant. This result could be exploited for HHP of low acid foods and biological materials.

High reduction in number of $E$. coli $\left(5.0 \mathrm{log}\right.$ reduction of $\left.\mathrm{CFU} \cdot \mathrm{ml}^{-1}\right)$ in frozen orange juice samples with $\mathrm{pH} 3.2$ after a $10 \mathrm{~min}$ at $250 \mathrm{MPa}$ and $20^{\circ} \mathrm{C}$ implies that for industrial applications lowering the process temperature near zero may not be necessary as long as the fruit juice is frozen before pressurizing under optimal set of parameters. Pressurization can be carried out at $4{ }^{\circ} \mathrm{C}$ or $20^{\circ} \mathrm{C}$, while the freezing of the food could take place separately at an earlier stage. This set up makes the pressurization of some liquid foods in frozen sate commercially feasible as a 5 -fold decrease in the initial population of pertinent pathogens could be achieved as per the recommendations of FDA. This study establishes some ground for further studies that need to focus on testing different pathogenic microorganisms and enzymes in various liquid foods. Studies on maximizing the bacterial reduction while keeping the optimum quality and shelf life of foods needed. Packaging size of the 
pressurised liquid food could be a critical factor, which needs to be further investigated for optimization of HHP of frozen liquid foods at an industrial scale. The balance between the economy of lower cost of equipment manufacturing and running costs as a result of operating at significantly reduced pressures and the cost increase due to freezing prior to pressurization also needs to be looked at.

\section{ACKNOWLEDGEMENTS}

This work was carried out at the laboratories of School of Chemistry, Food \& Pharmacy, and Department of Food \& Nutritional Sciences at Reading University. The corresponding author acknowledges the financial support of Trakya University during his sabbatical term at Reading University. The authors thank Apostolos Zacharakis and Fokion Kaldis for their assistance during conducting experiments and preparation of samples for SEM images. Amanpreet Kaur is thanked for her excellent support during all stages of SEM imaging.

\section{REFERENCES}

Alizadeh, E., Chapleau, N., de Lamballerie, M., \& Le-Bail, A. (2007). Effect of different freezing processes on the microstructure of Atlantic salmon (Salmo salar) fillets. Innovative Food Science \& Emerging Technologies, 8(4), 493-499.

Alpas, H., Kalchayanand, N., Bozoglu, F., \& Ray, B. (2000). Interactions of high hydrostatic pressure, pressurization temperature and $\mathrm{pH}$ on death and injury of pressure-resistant and pressure-sensitive strains of foodborne pathogens. International Journal of Food Microbiology, 60(1), 33-42.

Bevilacqua, A., Petruzzi, L., Perricone, M., Speranza, B., Campaniello, D., Sinigaglia, M., \& Corbo, M. R. (2018). Nonthermal Technologies for Fruit and Vegetable Juices and Beverages: Overview and Advances. Comprehensive Reviews in Food Science and Food Safety, 17(1), 2-62.

Bulut, S. (2014). The Effects of High-Pressure Processing at Low and Subzero Temperatures on Inactivation of Microorganisms in Frozen and Unfrozen Beef Mince Inoculated with Escherichia coli Strain ATCC 25922. Food and Bioprocess Technology, 1-12.

Bulut, S. (2014b). Inactivation of Escherichia coli in milk by high pressure processing at low and subzero temperatures. High Pressure Research, 34(4), 439-446.

Chaplin, M. (2018). Water Phase Diagram. In (Vol. 2018). UK.

Desjardins, P., \& Conklin, D. (2010). NanoDrop microvolume quantitation of nucleic acids. Journal of visualized experiments : JoVE(45), 2565.

Ekonomou, S. I., Bulut, S., Karatzas, K. A. G., \& Boziaris, I. S. (2020). Inactivation of Listeria monocytogenes in raw and hot smoked trout fillets by high hydrostatic pressure processing combined with liquid smoke and freezing. Innovative Food Science \& Emerging Technologies, 64, 102427.

Erkmen, O., \& Bozoglu, T. F. (2016). Food Microbiology, 2 Volume Set: Principles Into Practice: Wiley. 
FDA. (2001). Guidance for Industry: Questions and Answers on Juice HACCP Regulation. In: Office of Foods and Veterinary Medicine, Center for Food Safety and Applied Nutrition.

FDA. (2004). Guidance for Industry: Juice Hazard Analysis Critical Control Point Hazards and Controls Guidance. In ( First ed.): Office of Foods and Veterinary Medicine, Center for Food Safety and Applied Nutrition.

Hiperbaric. (2020). HPP beverages, evolution of demand in 2020. In (pp. Hiperbaric): Hiperbaric.

Huang, H.-W., Wu, S.-J., Lu, J.-K., Shyu, Y.-T., \& Wang, C.-Y. (2017). Current status and future trends of high-pressure processing in food industry. Food Control, 72, 1-8.

Institute of Food Technologists, U. S. F. D. A. (2000). Kinetics of Microbial Inactivation for Alternative Food Processing Technologies: IFT's Response to Task Order \#1, U.S. Food and Drug Administration : How to Quantify the Destruction Kinetics of Alternative Processing Technologies: Institute of Food Technologists.

Kelebek, H., Selli, S., Canbas, A., \& Cabaroglu, T. (2009). HPLC determination of organic acids, sugars, phenolic compositions and antioxidant capacity of orange juice and orange wine made from a Turkish cv. Kozan. Microchemical Journal, 91(2), 187-192.

Lambert, R. J., \& Stratford, M. (1999). Weak-acid preservatives: modelling microbial inhibition and response. Journal of Applied Microbiology, 86(1), 157-164.

LeBail, A., Chevalier, D., Mussa, D. M., \& Ghoul, M. (2002). High pressure freezing and thawing of foods: a review. International Journal of Refrigeration, 25(5), 504-513.

Luscher, C., Balasa, A., Fröhling, A., Ananta, E., \& Knorr, D. (2004). Effect of High-PressureInduced Ice I-to-Ice III Phase Transitions on Inactivation of Listeria innocua in Frozen Suspension. Applied and Environmental Microbiology, 70(7), 4021-4029.

Neidhardt, F. C., \& Kushner, S. R. (2017). Escherichia coli $九$. In Reference Module in Life Sciences: Elsevier.

Picart, L., Dumay, E., Guiraud, J.-P., \& Cheftel, J. C. (2004). Microbial inactivation by pressure-shift freezing: effects on smoked salmon mince inoculated with Pseudomonas fluorescens, Micrococcus luteus and Listeria innocua. LWT - Food Science and Technology, 37(2), 227-238.

Picart, L., Dumay, E., Guiraud, J. P., \& Cheftel, C. (2005). Combined high pressure-sub-zero temperature processing of smoked salmon mince: phase transition phenomena and inactivation of Listeria innocua. Journal of Food Engineering, 68(1), 43-56.

Rivalain, N., Roquain, J., \& Demazeau, G. (2010). Development of high hydrostatic pressure in biosciences: Pressure effect on biological structures and potential applications in Biotechnologies. Biotechnology Advances, 28(6), 659-672.

Shen, T., Urrutia Benet, G., Brul, S., \& Knorr, D. (2005). Influence of high-pressure-lowtemperature treatment on the inactivation of Bacillus subtilis cells. Innovative Food Science \& Emerging Technologies, 6(3), 271-278.

Shiba, T., \& Furushita, M. (2017). Pressure-induced inactivation of bacteria through pressureassisted thawing using a thermal buffer zone. Innovative Food Science \& Emerging Technologies, 39, 19-24.

Smelt, J. P. P. M. (1998). Recent advances in the microbiology of high pressure processing. Trends in Food Science \& Technology, 9(4), 152-158.

Souzu, H. (1980). Studies on the damage to Escherichia coli cell membrane caused by different rates of freeze-thawing. BBA - Biomembranes, 603(1), 13-26. 
Su, G., Yu, Y., Ramaswamy, H. S., Hu, F., Xu, M., \& Zhu, S. (2014). Kinetics of Escherichia coli inactivation in frozen aqueous suspensions by high pressure and its application to frozen chicken meat. Journal of Food Engineering, 142(0), 23-30.

Torres, E. F., González-M, G., Klotz, B., \& Rodrigo, D. (2016). Effects of high hydrostatic pressure and temperature increase on Escherichia coli spp. and pectin methyl esterase inactivation in orange juice. Food Science and Technology International, 22(2), 173180.

Volkert, M., Ananta, E., Luscher, C., \& Knorr, D. (2008). Effect of air freezing, spray freezing, and pressure shift freezing on membrane integrity and viability of Lactobacillus rhamnosus GG. Journal of Food Engineering, 87(4), 532-540.

Zhou, B., Zhang, L., Wang, X., Dong, P., Hu, X., \& Zhang, Y. (2019). Inactivation of Escherichia coli O157:H7 by High Hydrostatic Pressure Combined with Gas Packaging. In Microorganisms (Vol. 7).

Zhu, S., Wang, C., Ramaswamy, H. S., \& Yu, Y. (2017). Phase transitions during high pressure treatment of frozen carrot juice and influence on Escherichia coli inactivation. $L W T$ Food Science and Technology, 79, 119-125. 